\title{
A Study on Mechanical Properties of Silicon Carbide, E-Glass and Red Mud Reinforced Aluminium (LM25) Composite.
}

\author{
Mr. Prasanna ${ }^{1}$, Mr. Devraj ${ }^{2}$, Mr. Rakeshkumar $^{3}$, Mr. Mahadevappa $^{4}$, \\ Asst Prof. Sharanabasappa R $\mathrm{P}^{5}$ \\ ${ }^{1}$ B.E. in Mechanical Engineering, Department of Mechanical Engineering, AIET Gulbarga. \\ ${ }^{2}$ B.E. in Mechanical Engineering, Department of Mechanical Engineering, AIET Gulbarga. \\ ${ }^{3}$ B.E. in Mechanical Engineering, Department of Mechanical Engineering, AIET Gulbarga. \\ ${ }^{4}$ B.E. in Mechanical Engineering, Department of Mechanical Engineering, AIET Gulbarga. \\ ${ }^{5}$ Asst.Professor, Mechanical department, Appa Institute of Engineering \& Technology Gulbarga
}

\begin{abstract}
In this paper results of an experimental investigation of the mechanical properties of $\mathrm{SiC}, \mathrm{E}$-Glass and Red mud reinforced aluminium alloy (LM25) composites samples, processed by stir casting route are reported and analyzed. Four sets of composites with constant weight fraction of two reinforcements and varying one reinforcement ( 3 Sets) and a base metal specimen. The main mechanical properties studied were the tensile strength, ductility impact strength \&hardness. Unreinforced LM25 samples were also tested for the same properties. In our study we varied the reinforcing material in smaller quantity to avoid the mixing problem. And from the results what we got shows the addition of reinforcing materials like Red mud, E-Glass and SiC improves tensile strength, Impact strength and reduces \% Elongation. But addition of E-Glass minimizes the hardness.
\end{abstract}

Key Words: LM25 Aluminum Alloy, Silicon carbide, E-glass, Red mud and LM25 Mechanical properties.

\section{Introduction}

Composite material is the material having two or more distinct phases like matrix phase and reinforcing phase and having bulk properties significantly different from those of any of the constituents present in the matrix material. Composite materials are preferred over other metals and non metals because of some favorable properties they are having. The favorable properties are, high stiffness and high tensile strength, low density, high temperature stability, and also in some of the applications electrical and thermal conductivity properties are also taken into consideration, the properties like coefficient of thermal expansion, corrosion resistance are also low with improved wear resistance. To improve fuel efficiency in automobiles the bodies are manufactured with the composite materials, So that the automobile body mass can be kept low by improving fuel efficiency. Nano carbon fiber reinforced aluminium composites are already in use. Mainly aluminium composite materials are having more scope because of its light weight and availability on earth. Because of all these possibilities with the aluminium composites the related studies are always on and our study is one among them. In every study the base material properties are altered by adding some reinforcements the resulted properties are analyzed and based on the properties, suitable application areas are suggested. Before preparing the aluminium metal matrix composite material, we have studied some papers in which the addition of $\mathrm{SiC}$ and red mud into Aluminium (LM25) metal alloy and mechanical properties were studied. Few of them are as follows.

Akhilesh Jayakumar, Mahesh Rangaraj, studies on Property Analysis of Aluminium (LM25) Metal Matrix with $\mathrm{SiC}$ as reinforced material. They found that, functionally graded composite cylinder shows higher hardness towards the outer periphery, due to the presence of high volume fraction of silicon carbide particles.

Neelima Devi. C, Mahesh.V, Selvaraj. $N$ studies on Mechanical characterization of Aluminium silicon carbide composite. They found that, the maximum tensile strength has been obtained at $15 \% \mathrm{SiC}$ ratio. This indicates that the Aluminium silicon carbide composite material is having less weight and more strength; it is very much useful in practical aerospace applications.

Md.AzharFarooqManiyar, B.S.Motgi studies on microstructure and tribological characteristics of $1 \mathrm{~m} 25 / \mathrm{SiC}$ /mica-hybrid MMC's. They found that, Mica mixed with $\mathrm{SiC}$ makes the material harder up to a certain limit. Prepared MMC's provide excellent wear characteristics up to a limit load. The tensile strength improves for $10 \%$ addition of $\mathrm{SiC}$. The $10 \% \mathrm{SiC}$ and $2 \%$ Mica is the best possible mixture for ideal usage of aluminium. The material tends to wear up to addition of $5 \%$ of $\mathrm{SiC}$ rapidly. Lower the load applied higher the wear for $5 \%$ addition of $\mathrm{SiC}$. Therefore the characteristics of phase constituents play important role on these alloys. The highest wear rate is measured in $5 \% \mathrm{SiC}$. 
- Manoj Singla, D. Deepak Dwivedi, Lakhvir Singh, Vikas Chawla studies on Development of Aluminium Based Silicon Carbide Particulate Metal Matrix Composite. They found that, the results of study suggest that with increase in composition of $\mathrm{SiC}$, an increase in hardness, impact strength and normalized displacement have been observed. The best results has been obtained at $25 \%$ weight fraction of 320 grit size SiC particles. Maximum Hardness $=45.5 \mathrm{BHN} \&$ Maximum Impact Strength $=36 \mathrm{~N}-\mathrm{m}$.

S. Rajesh, S. Rajakarunakaran, R. Suthakarapandian, and P. Pitchipoo. MOORA-Based Tribological Studies on Red Mud Reinforced Aluminum Metal Matrix Composites. They found that, for the lowest specific wear rate, $10 \mathrm{~N}$ applied load, $4 \mathrm{~m} / \mathrm{s}$ sliding speed, $25 \mathrm{wt} \%$ of reinforcement, and $62 \mathrm{HRC}$ counter face hardness of the material were used. For the lowest coefficient of friction, $10 \mathrm{~N}$ applied load, $4 \mathrm{~m} / \mathrm{s}$ sliding speed, $15 \mathrm{wt} \%$ of reinforcement, and 62HRC counter face hardness of the material were used.

K.Annamalai, Ramangouda Patil, Arjun C C, VenugopalPillarisetti, studies on influence of e-glass and graphite particle on al-356 alloy (LM 25 alloy) composite. They found that, Present work in the paper unveils that aluminium hybrid composites are successfully produced by Vortex method with $1.25 \%$ each and $2.5 \%$ each of E-glass fibers and Graphite particles by weight. The macrostructure study reveals the fact that the cast specimens have no porosity and uniform distribution of reinforcement particles. A composite of $2.5 \%$ of both $\mathrm{E}$ glass fibres and graphite particles by weight shows substantial increase in hardness and wear resistance in comparison to the one of $1.25 \%$ which offers better compressive strength.

Basavaraju.S Arasukumar.K Dr.Chandrashekhar Bendigeri Dr.C.K.Umesh Studies on Mechanical Properties and Tribological Characteristics of LM25- Graphite- Silicon Carbide and LM25-Flyash- Silicon Carbide - Hybrid MMC's. They found that, Graphite and Fly ash mixed with SiC makes the material harder up to a certain limit. Prepared MMC's provide excellent wear characteristics up to a limit load. The tensile strength improves for $2 \%$ addition of $\mathrm{SiC}$ and $4 \%$ of $\mathrm{SiC}$ in $\mathrm{Al}+\mathrm{Graphite}$. This proportion is ideal for many results to outcome easily. Similarly, $2 \%$ and $4 \%$ addition of $\mathrm{SiC}$ in Flyash combination makes a efficient material. The hardness of the material increases with the combination of $2 \%$ addition of $\mathrm{SiC}$ and Graphite. The compressive strength is ideal at $2 \%$ and $4 \%$ addition of $\mathrm{SiC}$ graphite and Flyash.

The $2 \% \mathrm{SiC}$ and $2 \%$ Graphite is the best possible mixture for ideal usage of aluminium. The material tends to wear up to addition of $4 \%$ of SiC rapidly. Lower the load applied higher the wear for $2 \%$ to $8 \%$ addition of SiC. Therefore the characteristics of phase constituents play important role on these alloys. The highest wear rate is measured in $8 \% \mathrm{SiC}$. Here the hardness of the alloy makes it unable to bear the wear.

Comparing the density and cost of the alloys suggests that the alloys containing $2 \%$ and $4 \%$ SiC would be cost effective and energy efficient for wear and strength applications.

From the above literature survey, it can conclude that, the influence of different $\%$ wt of SiC with $\%$ wt of E-glass and red mud on mechanical properties of Aluminium LM25 has been taken for study. And effort has been made to show the effect of reinforcement and its \%wt variation on the mechanical properties to make it as a useful material in engineering field.

\subsection{Specimen Preparation.}

\section{Experimental Procedure.}

The materials used to prepare specimens are LM25, SiC, and E-glass and Red mud. The specimens are prepared by machining the stir casted parts. For stir casting induction furnace is used. First the base metal is taken in a furnace and heated to $600^{\circ} \mathrm{C}$. When base metal melts at that temperature the preheated reinforcements are added to the molten base metal. Then to have self stirring process temperature of the furnace is raised to $800^{\circ} \mathrm{C}$ and also the stirring is done with the help of stirring mechanism at 300 RPM. The following figures show the step by step casting and specimen preparation processes.

Step 1: LM25 is taken in an induction furnace as shown in below fig 2.1.

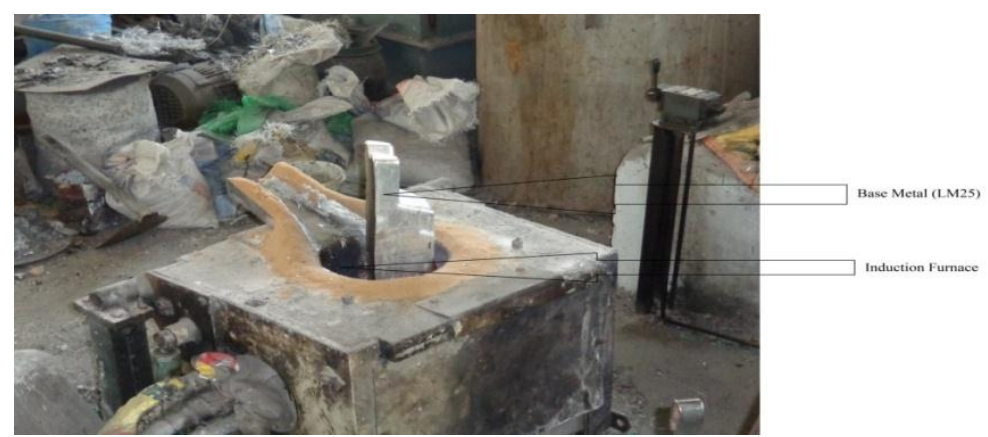

Fig: 2.1 
Step 2: The melting is done by raising furnace temperature up to $600^{\circ} \mathrm{C}$ as shown in below fig 2.2 .

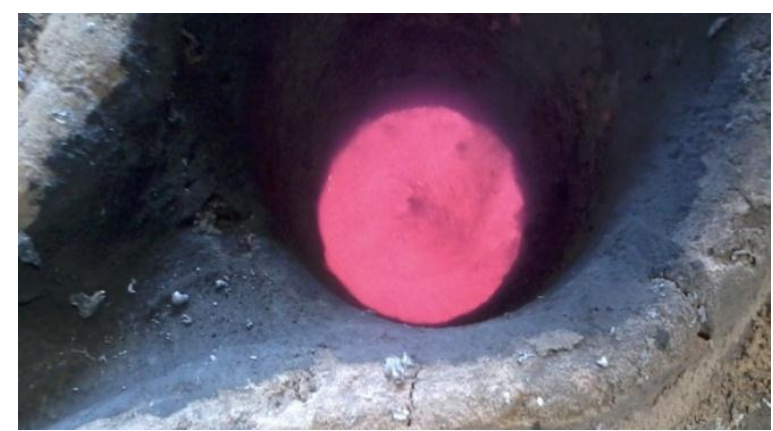

Fig: 2.2

Step 3: Pre heated $\left(300^{\circ} \mathrm{C}\right)$ reinforcements are added to the molten metal one by one and stirred as shown in below fig 2.3 .

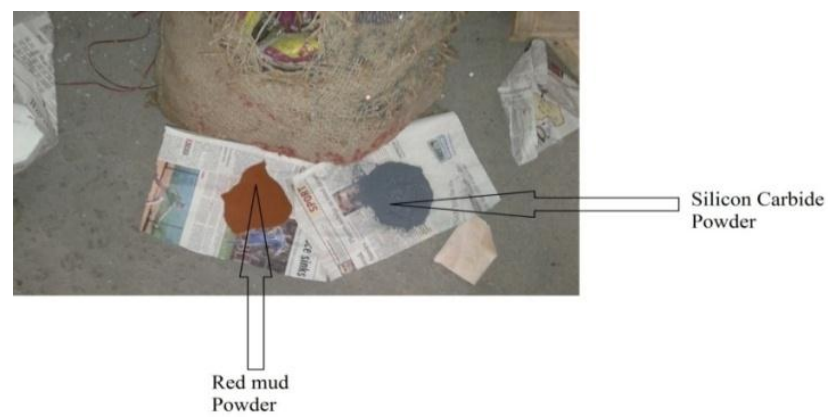

Fig: 2.3

Step 4: The cast iron die pre heated $\left(100^{\circ} \mathrm{C}\right)$ as shown in below fig 2.4 .

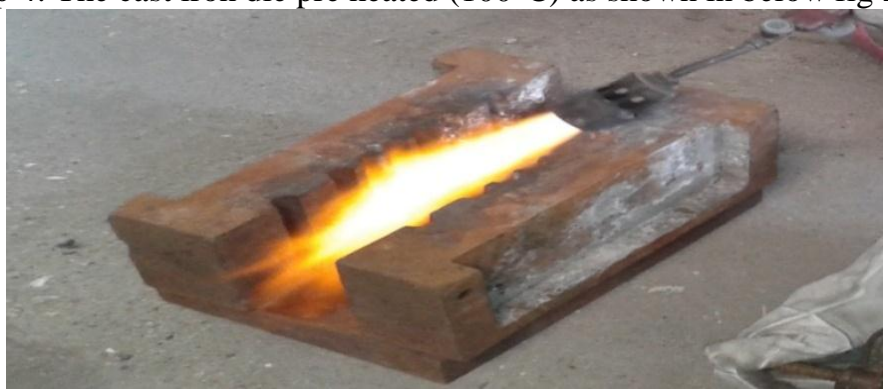

Fig: 2.4

Step 5: Molten metal is pouring into the laddel first, (fig 2.5) then this molten metal poured into die.

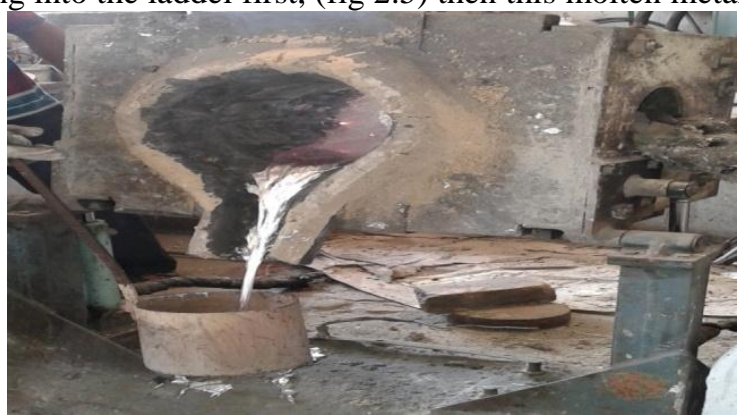

Fig: 2.5

Step 6: Stir casted parts are taken out from the die after 10 minutes of pouring and naturally cooled as shown in below fig 2.6 . 


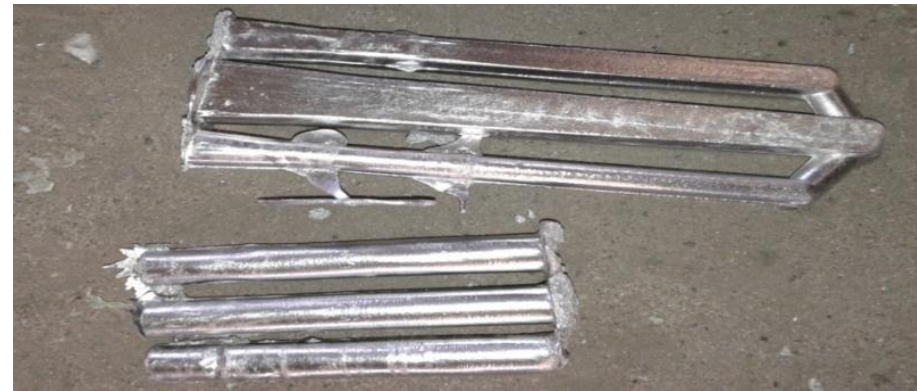

Fig 2.6

Step 7: The Casted parts are machined to get the required specimens for different tests as shown in below fig 2.7 .

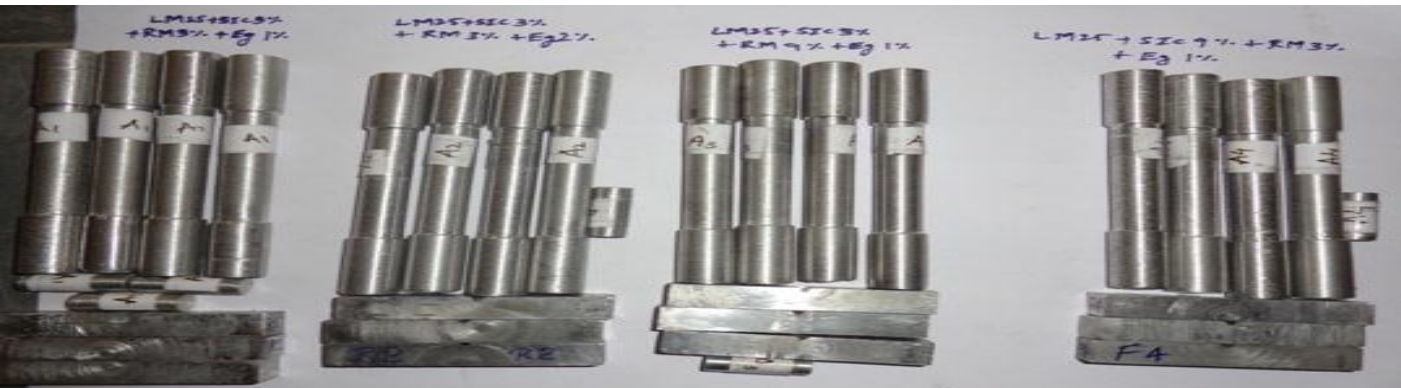

Fig: 2.7

\subsection{Testing Of Mechanical Properties:}

The specimens are prepared as per BS:18:1962 standard. The tensile tests were conducted on these samples at room temperature, using a universal testing machine. The tensile test specimen dimensions are $50 \mathrm{~mm}$ guage length and $10 \mathrm{~mm}$ diameter, grip lengths are $25 \mathrm{~mm}$ and $12 \mathrm{~mm}$ diameter. The charpy specimen and Hardness test specimens of required dimensions are also kept ready.

\section{Microscopic Study:}

\section{Results And Discussion}

The microscopic study is very important to see the distribution of the reinforced particles in the metal matrix. In our study we have done microscopic study with the help of optical microscope. And results shows that the reinforced particles are near uniformly distributed and hence we can go for further studies.

The images are as below.

Image 3a: Micro structure of LM25 with $1 \%$ E-glass, 3\% red mud, and $3 \%$ silicon carbide.

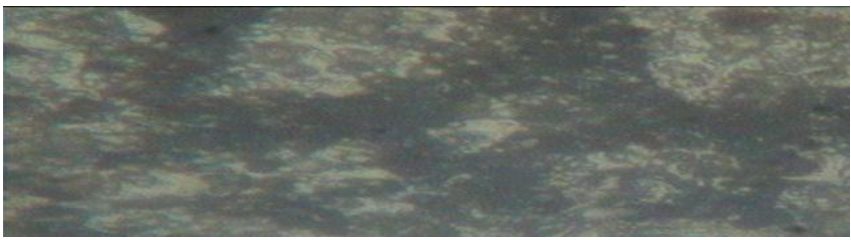

Image 3a

Image 3b: Micro structure of LM25 with $2 \%$ E-glass, 3\% red mud, and $3 \%$ silicon carbide.

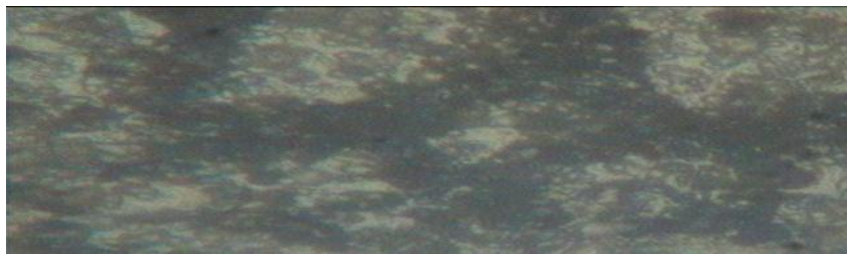

Image 3b 
Image 3c: Micro structure of LM25 with $1 \%$ E-glass, $9 \%$ red mud, and $3 \%$ silicon carbide.

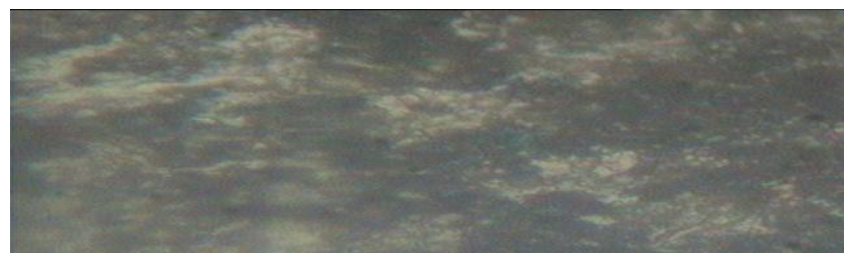

Image 3c

Image 3d: Micro structure of LM25 with 1\% E-glass, 3\% red mud, and $9 \%$ silicon carbide.

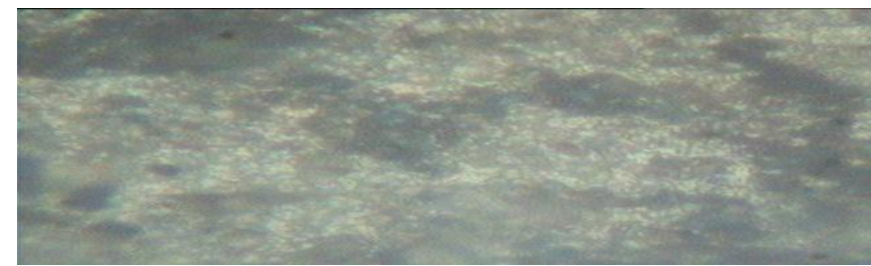

Image 3d

3.1: Tensile Property Test.

3.1.1: Tensile properties of a specimen having varying weight $\%$ of E-Glass and Constant weight $\%$ of Red mud and $\mathrm{SiC}$.

Table 3.1.1

\begin{tabular}{|c|l|l|l|l|}
\hline $\begin{array}{c}\text { LM 25 } \\
(\mathrm{BASE})\end{array}$ & E-glass (\%) & $\mathrm{SiC}(\%)$ & Red mud (\%) & Tensile strength(MPa) \\
\hline & 1 & 3 & 3 & 204 \\
\hline & 2 & 3 & 3 & 216 \\
\hline & 3 & 3 & 3 & 229 \\
\hline
\end{tabular}

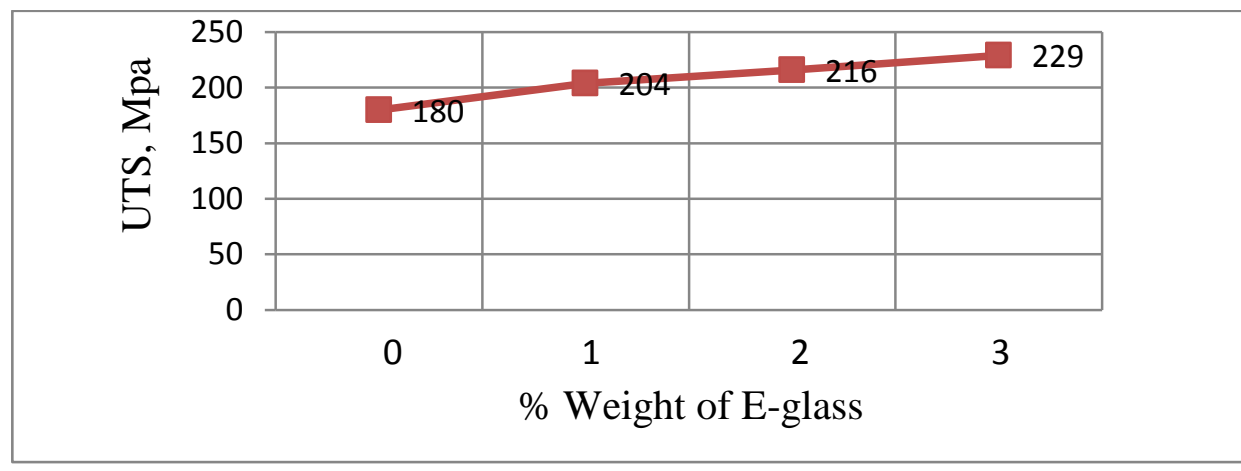

Graph: 3.1.1

From the above graph it can be seen that the tensile strength of the composite increased as weight $\%$ of E-glass has been increased. Because already the E-Glass is having very high tensile strength in its own. When it is added to the matrix it improves its tensile property also. The first value (180 MPa) shown in above graph is the tensile strength of Base metal (LM25).

3.1.2: Tensile properties of a specimen having varying weight $\%$ of Red mud and Constant weight $\%$ of $E$ Glass and SiC.

Table: 3.1.2

\begin{tabular}{|l|l|l|l|l|}
\hline LM 25 (BASE) & E-glass (\%) & SiC (\%) & Red mud (\%) & $\begin{array}{l}\text { Tensile } \\
\text { strength(MPa) }\end{array}$ \\
\hline & 1 & 3 & 3 & 191 \\
\hline & 1 & 3 & 6 & 204 \\
\hline & 1 & 3 & 9 & 216 \\
\hline
\end{tabular}




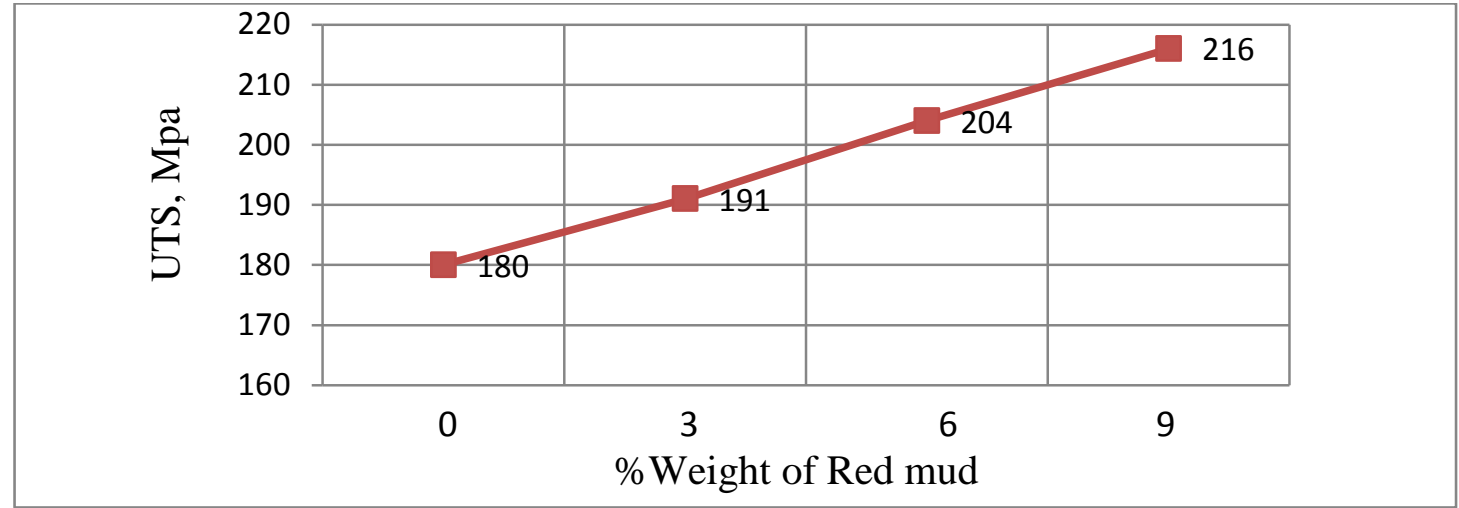

Graph 3.1.2

In graph 3.1.2 it has been observed that the tensile strength also increases with increase in weight $\%$ of red mud. In our study we considered weight $\%$ from 0 to $9 \%$.Excess addition may reduce the strength of material because of poor wettability. As per in our study is concerned we got improved tensile property up to 9\%.Redmud is plenty and cheaply (almost Zero cost) available material, hence it can be used to improve the tensile property of the material.

3.1.3: Tensile properties of a specimen having varying weight $\%$ of $\mathrm{SiC}$ and Constant weight $\%$ of $\operatorname{Red}$ mud and E-Glass.

Table 3.1.3

\begin{tabular}{|l|l|l|l|l|}
\hline LM 25 (BASE) & E-glass (\%) & SiC (\%) & Red mud (\%) & Tensile strength(MPa) \\
\hline & 1 & 3 & 3 & 191 \\
\hline & 1 & 6 & 3 & 216 \\
\hline & 1 & 9 & 3 & 229 \\
\hline
\end{tabular}

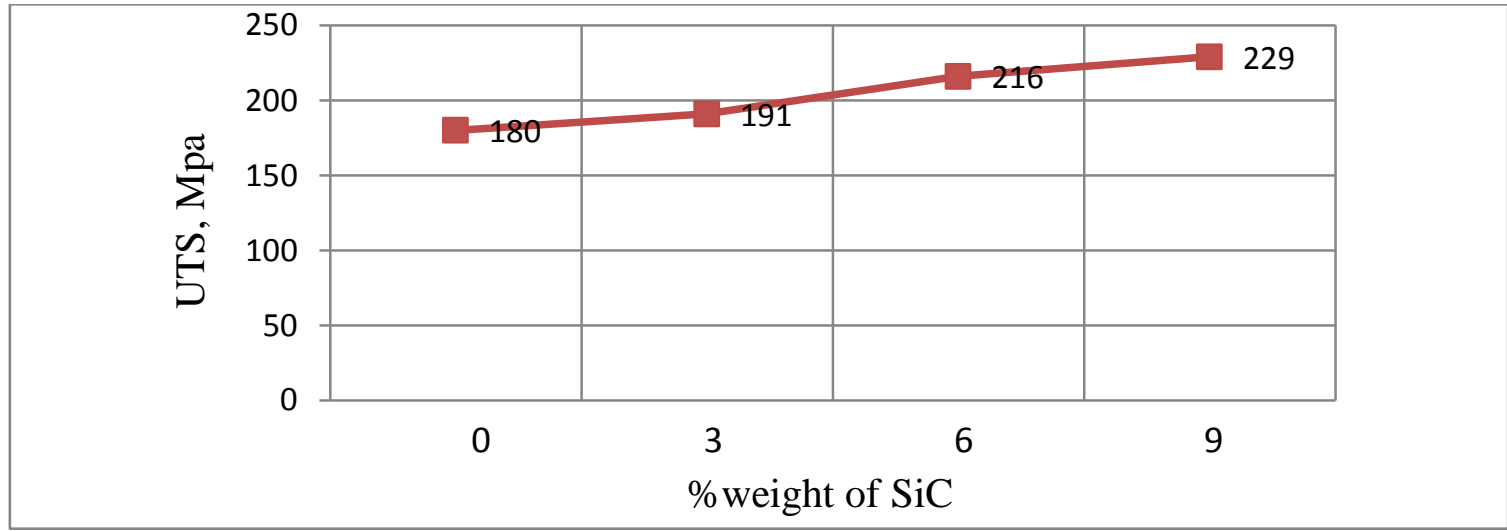

Graph: 3.1.3

From the above graph3.1.3 it can be observed that the addition of $\mathrm{SiC}$ at a limited \%weight into the metal matrix improves the tensile strength of the material. Here also the excess quantity may reduce the value of the mechanical properties because of the poor wettability between the particles and matrix. But as per our study the properties are improved by adding $\mathrm{SiC}$ up to the limit which is shown in above graph.

\subsection{Impact test.}

\subsection{1: Variation of energy absorption before failure with \% weight variation of E-glass}

Table 3.2.1

\begin{tabular}{|l|l|l|l|l|}
\hline LM 25 (BASE) & E-glass (\%) & SiC (\%) & Red mud (\%) & $\begin{array}{l}\text { Impact strength } \\
(\text { kg-m) }\end{array}$ \\
\hline & 1 & 3 & 3 & 4 \\
\hline & 2 & 3 & 3 & 5.3 \\
\hline & 3 & 3 & 3 & 6.6 \\
\hline
\end{tabular}




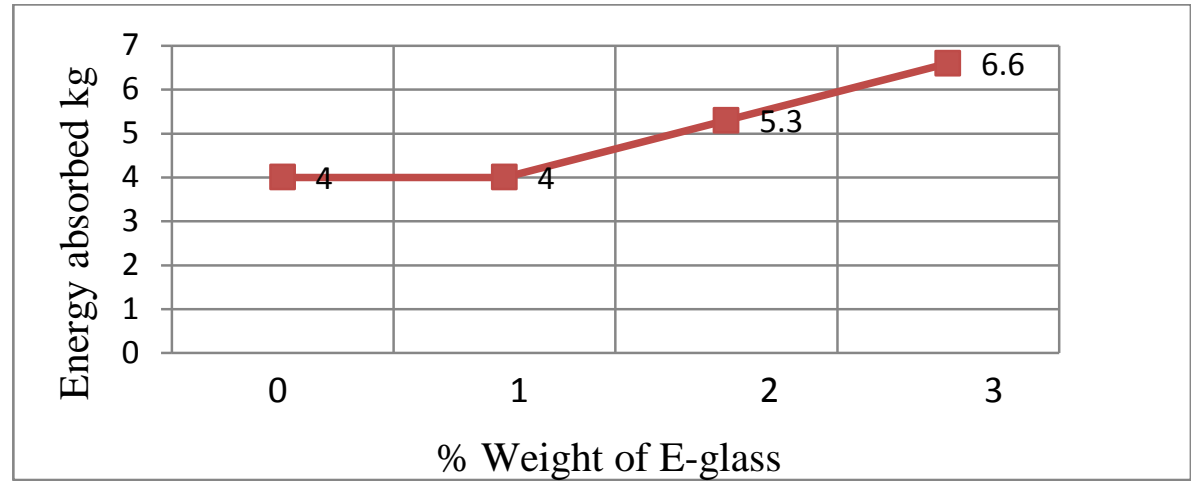

Graph: 3.2.1

Impact strength is nothing but energy absorbed before failure when a sudden load is applied on an object. We have done the charpy test to know the impact strength of the prepared aluminium composite specimen. The graph shows the addition of E-Glass improves the impact strength of the composite material. The first value (4 Kg-m) shown in above graph is the energy absorption of Base metal (LM25).

\subsection{2: Variation of energy absorption before failure with \% weight variation of SiC}

Table: 3.2.2

\begin{tabular}{|l|l|l|l|l|}
\hline LM 25(BASE) & E-glass (\%) & SiC (\%) & Red mud (\%) & $\begin{array}{l}\text { Impact strength } \\
(\mathrm{kg}-\mathrm{m})\end{array}$ \\
\hline & 1 & $\mathbf{3}$ & $\mathbf{3}$ & $\mathbf{4}$ \\
\hline & 1 & 6 & 3 & 5.3 \\
\hline & 1 & 9 & 3 & 6.6 \\
\hline
\end{tabular}

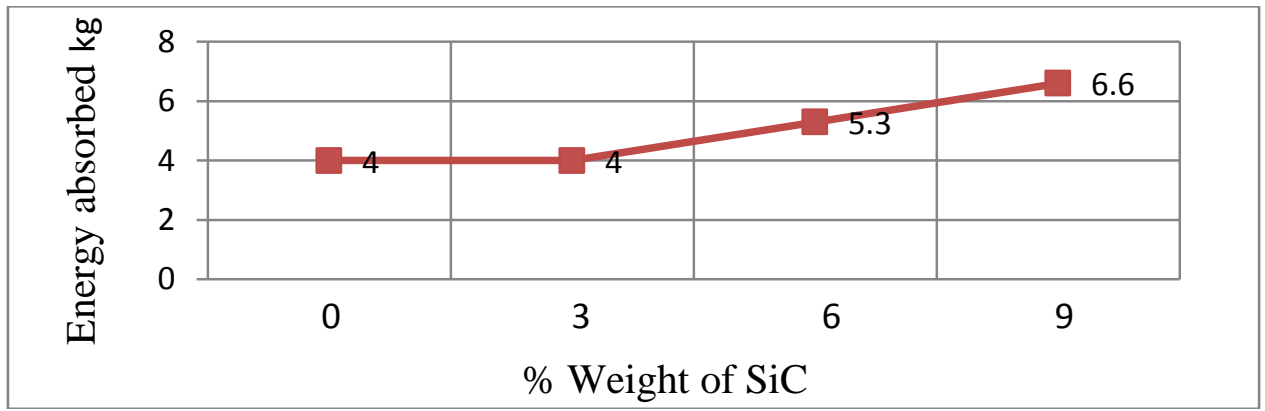

Graph: 3.2.2

From the above graph we can say that the impact strength gone high after the addition of the SiC. But in few papers we have seen that excess addition of $\mathrm{SiC}$ into the Aluminium metal matrix may not mix uniformly. Because the density of the $\mathrm{SiC}$ is more than the Aluminium Alloy, hence the denser particles of $\mathrm{SiC}$ will settle down suddenly when we stop stirring. That is the reason in our study we varied very less to avoid this problem.

\subsection{3: Variation of energy absorption before failure with $\%$ weight variation of red mud}

Table 3.2.3

\begin{tabular}{|l|l|l|l|l|}
\hline LM 25 (BASE) & E-glass (\%) & SiC (\%) & Red mud (\%) & $\begin{array}{l}\text { Impact } \\
\text { strength (kg-m) }\end{array}$ \\
\hline & 1 & 3 & 3 & 5 \\
\hline & 1 & 3 & 6 & 8 \\
\hline & 1 & 3 & 9 & 12 \\
\hline
\end{tabular}




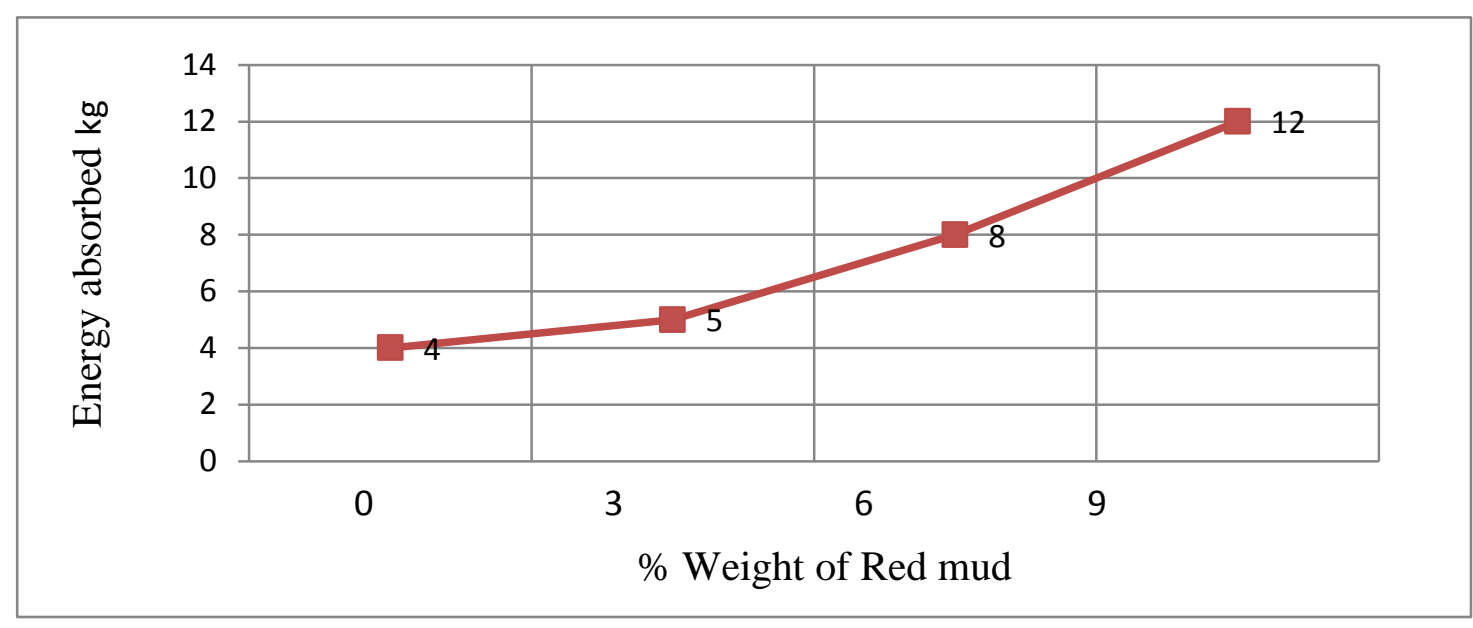

Graph 3.2.3

Above graph shows maximum impact strength, which is more than the strength obtained by adding $\mathrm{SiC}$ or E-Glass. Hence E-Glass and SiC need some cost to procure them but red mud is freely available in nature. Means we can add impact strength to the aluminium material with a less cost than the other two options.

\section{3: Hardness Test.}

3.3.1: Variation of BHN with \% weight variation of E-glass

Table 3.3.1

\begin{tabular}{|l|l|l|l|l|}
\hline LM 25 (BASE) & E-glass (\%) & SiC (\%) & Red mud (\%) & BHN \\
\hline & 1 & 3 & 3 & $\mathbf{8 1}$ \\
\hline & 2 & 3 & 3 & 70 \\
& 3 & 3 & 3 & 60 \\
\hline
\end{tabular}

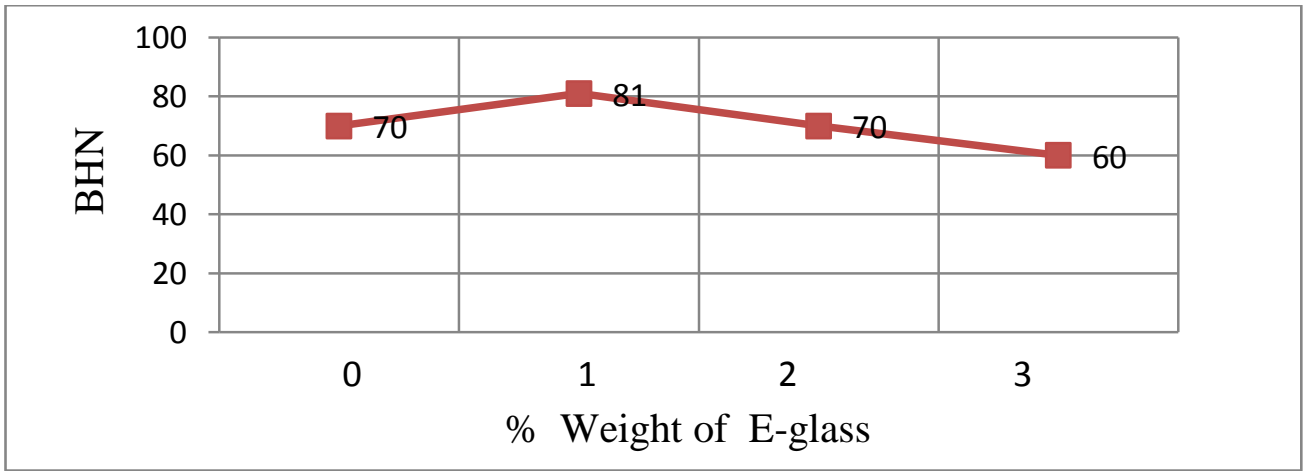

Graph 3.3.1

E-Glass is having a better tensile strength and we seen after adding it into the aluminium alloy which improved its tensile strength. But from above graph we can say that the E-glass is not preferable material to improve hardness property to the aluminium materials. The first value (70) shown in above graph is the BHN (Brinell Hardness Number) of Base metal (LM25).

\subsection{2: Variation of BHN with \% weight variation of silicon carbide}

Table 3.3.2

\begin{tabular}{|l|l|l|l|l|}
\hline LM 25 (BASE) & E-glass (\%) & SiC (\%) & Red mud (\%) & BHN \\
\hline & 1 & 3 & 3 & 81 \\
\hline & 1 & 6 & 3 & 82 \\
\hline & 1 & 9 & 3 & 83 \\
\hline
\end{tabular}




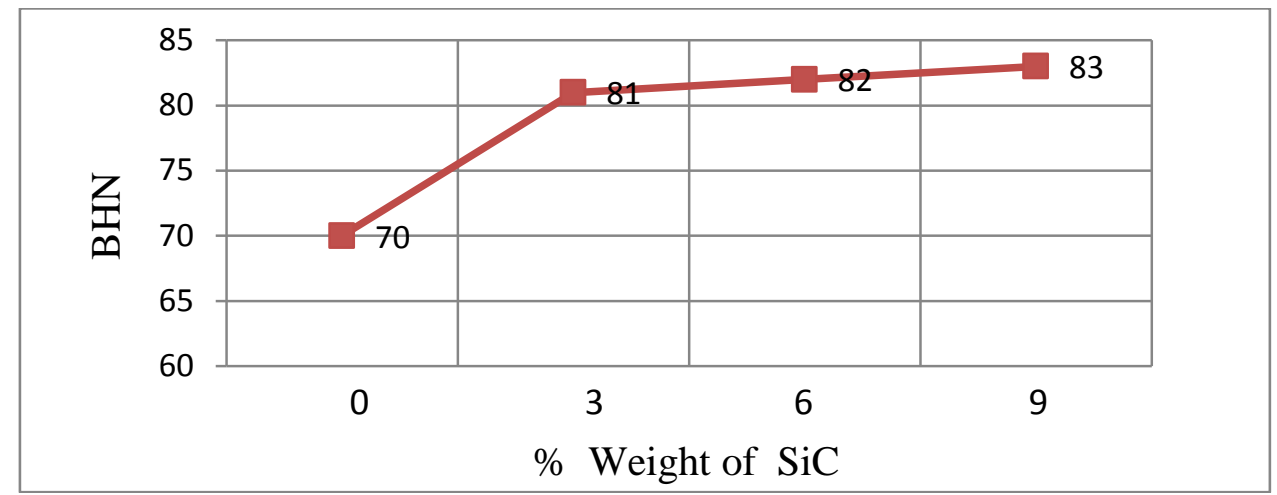

\section{Graph 3.3.2}

The graph shows the sudden change in hardness property of the composite after the addition and increase in weight $\%$ of $\mathrm{SiC}$. $\mathrm{SiC}$ it is a ceramic material having very high hardness in it. When we add it into the composite it restricts the indenter penetration that is the addition of $\mathrm{SiC}$ restricts the metallic deformation due to applied load on it.

\subsection{3: Variation of BHN with \% weight variation of Red mud}

Table 3.3.3

\begin{tabular}{|l|l|l|l|l|}
\hline LM 25 (BASE) & E-glass (\%) & SiC (\%) & Red mud (\%) & BHN \\
\hline & $\mathbf{1}$ & $\mathbf{3}$ & $\mathbf{3}$ & $\mathbf{8 1}$ \\
\hline & $\mathbf{1}$ & $\mathbf{3}$ & $\mathbf{6}$ & $\mathbf{8 1}$ \\
\hline & 1 & $\mathbf{3}$ & $\mathbf{9}$ & $\mathbf{8 2}$ \\
\hline
\end{tabular}

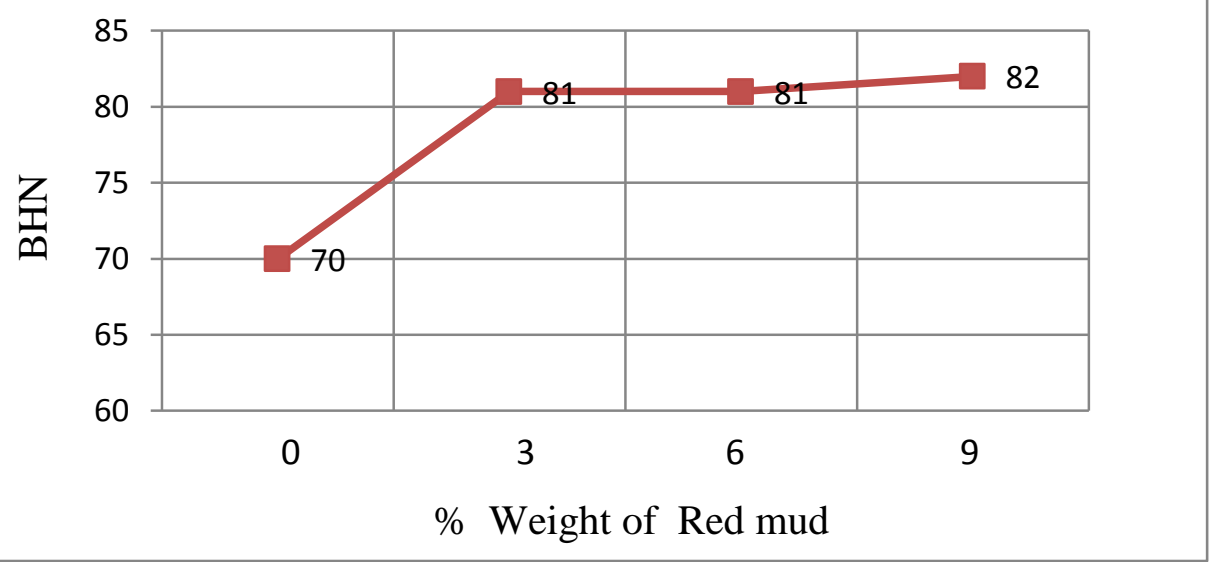

Graph 3.3.3

Addition of Red mud also shows the improvement in Hardness property. We can observe it in the above graph. And the hardness values are almost same in both the cases (Case1: Addition of SiC, Case2: Addition of Red mud).But addition of red mud is less costly than the addition of SiC. Hence as per our study, Case2 is preferred over case1.

\section{4: Ductility}

\subsection{1: Variation of \% Elongation with \% weight variation of E-glass}

Table 3.4.1

\begin{tabular}{|l|l|l|l|l|}
\hline LM 25 (BASE) & E-glass (\%) & SiC (\%) & Red mud (\%) & \% Elongation \\
\hline & 1 & 3 & 3 & 3 \\
\hline & 2 & 3 & 3 & 2.5 \\
\hline & 3 & 3 & 3 & 1 \\
\hline
\end{tabular}




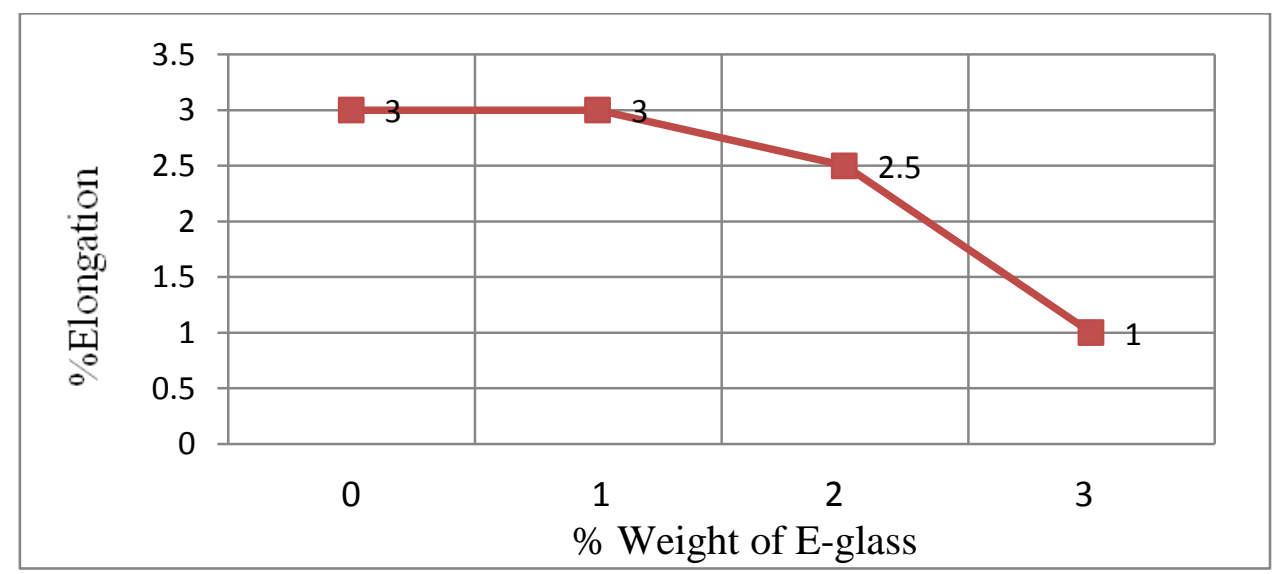

Graph 3.4.1

The first value (3) shown in above graph is the \% Elongation of Base metal (LM25).

\subsection{2: Variation of \% Elongation with \% weight variation of $\mathrm{SiC}$}

Table 3.4.2

\begin{tabular}{|l|l|l|l|l|}
\hline LM 25 (BASE) & E-glass (\%) & SiC (\%) & Red mud (\%) & \% Elongation \\
\hline & 1 & 3 & 3 & 2.5 \\
\hline & 1 & 6 & 3 & 2 \\
\hline & 1 & 9 & 3 & 1 \\
\hline
\end{tabular}

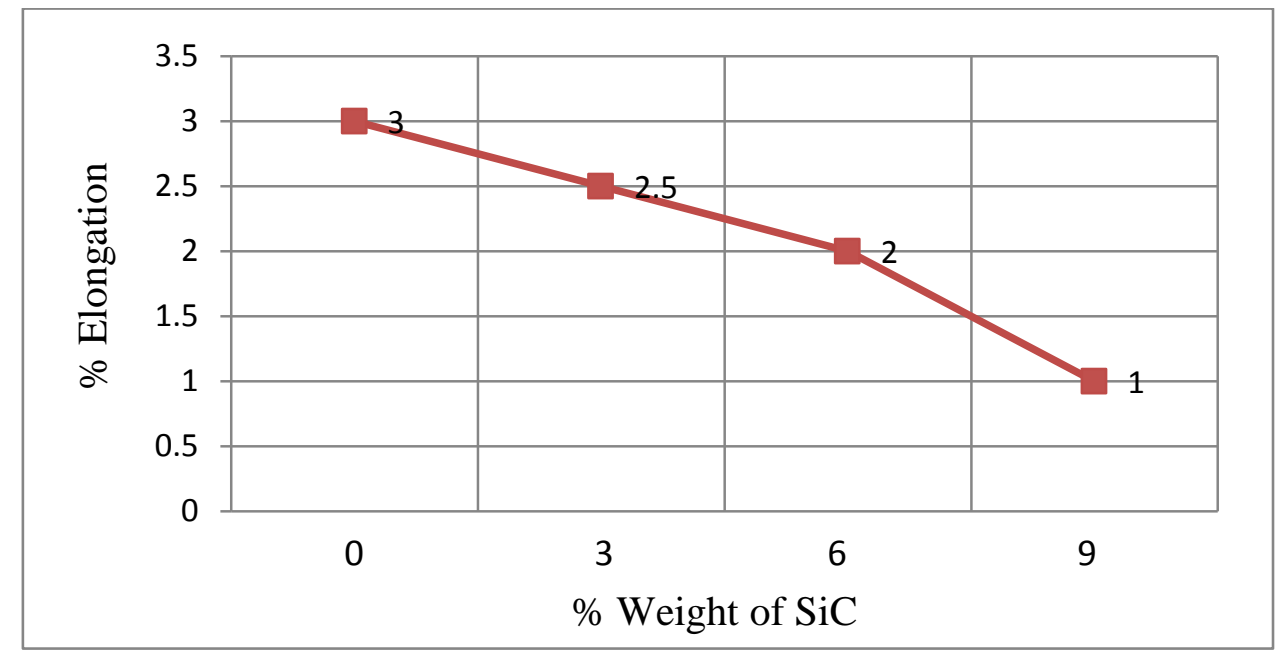

Graph 3.4.2

3.4.3: Variation of $\%$ Elongation with \% weight variation of Red mud

Table 3.4.3

\begin{tabular}{|l|l|l|l|l|}
\hline LM 25 (BASE) & E-glass (\%) & SiC (\%) & Red mud (\%) & \% Elongation \\
\hline & 1 & 3 & 3 & 2.5 \\
\hline & 1 & 3 & 6 & 2 \\
\hline & 1 & 3 & 9 & 1 \\
\hline
\end{tabular}




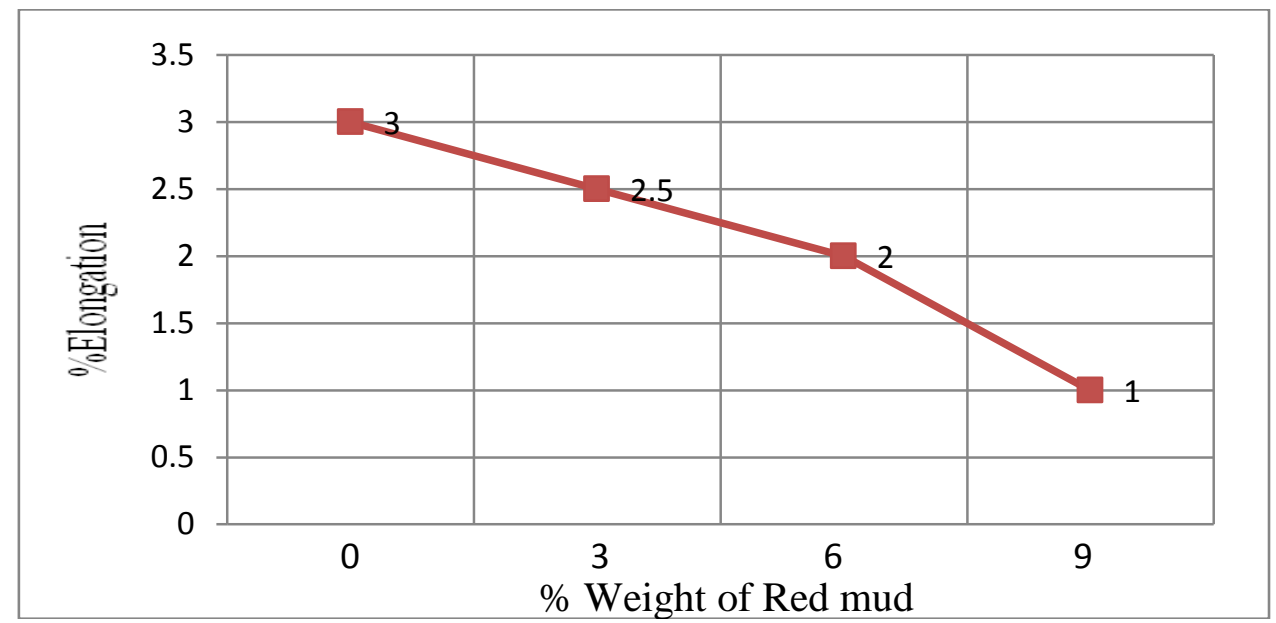

Graph 3.4.3

We can observe the \% Elongation In all the three cases (Case1: Varying SiC, Case2: Varying Red mud, Case3: Varying E-Glass). Which shows, varying any of the reinforcing component reduces the \% elongation. But according to us the red mud is added at a less cost case 2 is preferred to reduce \% elongation over other two.

\section{Conclusion.}

From the above experiment and result analysis we can conclude that, The By stir casting method we can easily produce aluminium composites. But as per our observation stirring becomes problem when we try to add excess quantity of reinforcements into the metal matrix and also it is tough to mix the reinforcing materials which are having very high or very low density than the matrix phase. If the density is very high than the metal matrix the reinforcement particles will settle down early when we stop stirring. If we add low density reinforcing materials they may float over the surface instead of distributing themselves in the metal matrix phase. But in our study we varied the reinforcing material in smaller quantity to avoid the mixing problem. And from the results what we got shows the addition of reinforcing materials like Red mud, E-Glass and SiC improves tensile strength, Impact strength and reduces \% Elongation. But addition of E-Glass minimizes the hardness.

\section{References}

[1] Mr.Sharanabasappa R Patil, Prof B.S Motgi, Studies on Mechanical Properties of Fly Ash and Alumina Reinforced Aluminium Alloy (LM25) Composites. IOSR Journal of Mechanical and Civil Engineering (IOSR-JMCE) e-ISSN: 2278-1684,p-ISSN: 2320-334X, Volume 7, Issue 6 (Jul. - Aug. 2013), PP 41-46

[2] Akhilesh Jayakumar, Mahesh Rangaraj, studies on Property Analysis of Aluminium (LM-25) Metal Matrix Composite. International Journal of Emerging Technology and Advanced Engineering Website: www.ijetae.com (ISSN 2250-2459, ISO 9001:2008 Certified Journal, Volume 4, Issue 2, February 2014)

[3] K.Annamalai, Ramangouda Patil, Arjun C C, Venugopal Pillarisetti, studies on influence of e-glass and graphite particle on al-356 alloy (LM 25 alloy) composite produced by vortex method. (IJEST).

[4] Neelima Devi. C, Mahesh.V, Selvaraj. N studies on Mechanical characterization of Aluminium silicon carbide composite. INTERNATIONAL JOURNAL OF APPLIED ENGINEERING RESEARCH, DINDIGUL Volume 1, No 4, 2011

[5] Md.AzharFarooqManiyar, B.S.Motgi studies on MICROSTRUCTURE AND TRIBOLOGICAL CHARACTERISTICS OF LM25/SIC/MICA-HYBRID MMC'S. International Journal of Advance Research, IJOAR .org Volume 1, Issue 8, August 2013,

[6] ManojSingla, D. Deepak Dwivedi, Lakhvir Singh, VikasChawla studies on Development of Aluminium Based Silicon Carbide Particulate Metal Matrix Composite. Journal of Minerals \& Materials Characterization \& Engineering, Vol. 8, No.6, pp 455-467, 2009

[7] A.K. PrasadaRao, K. Dasa, B.S. Murty, M. Chakraborty, Microstructural and wear behavior of hypoeutectic Al-Si alloy (LM25) grain refined and modified with Al-Ti-C-Sr master alloy. Received 31 October 2004; received in revised form 14 September 2005; accepted 21 September 2005Available online 21 October 2005

[8] Basavaraju.SArasukumar.KDr.ChandrashekharBendigeriDr.C.K.UmeshStudies on Mechanical Properties and Tribological Characteristics of LM25- Graphite- Silicon Carbide and LM25-Flyash- Silicon Carbide - Hybrid MMC's. International Journal of Innovative Research in Science, Engineering and Technology Vol. 1, Issue 1, November 2012.

[9] S. Rajesh, S. Rajakarunakaran, R. Suthakarapandian, and P. Pitchipoo. MOORA-Based Tribological Studies on Red Mud Reinforced Aluminum Metal Matrix Composites. 
[10] Harish K.Garg, ketanVerma, alakesh Manna, Rajesh kumar : paper on hybrid metal matrix composites and further improvement in their machinability (international journal of latest Research in science and technology Vol.1, Issue 1:36-44,may-june(2012) ISSN (online ):2278-5299)

[11] Jalees Ahemad, Prof. S.V. Bhaskar, Prof. R. A. Kapgate, Prof. N. D.Sadaphal, Prof. S. B. Kharde studies on Development of $\mathrm{Al} / \mathrm{Sic} 5 \%, \mathrm{Al} / \mathrm{Sic} 10 \%, \mathrm{Al} / \mathrm{Sic} 15 \%$, Metal Matrix Composite And Its Comparision With Alluminium Alloy - LM25 On Tribological Parameters. International Journal of Emerging Technology and Advanced Engineering Website: www.ijetae.com (ISSN 2250-2459, ISO 9001:2008 Certified Journal, Volume 3, Issue 9, September 2013)

[12] G. Elango, B.K.Raghunath studies on Tribological Behavior of Hybrid (LM25Al + SiC+ TiO2) Metal Matrix Composites. International Conference on DESIGN AND MANUFACTURING, IConDM 2013. 